C员员區
REPORT 86-9

A theory for the scalar roughness and the scalar transfer coefficients over snow and sea ice

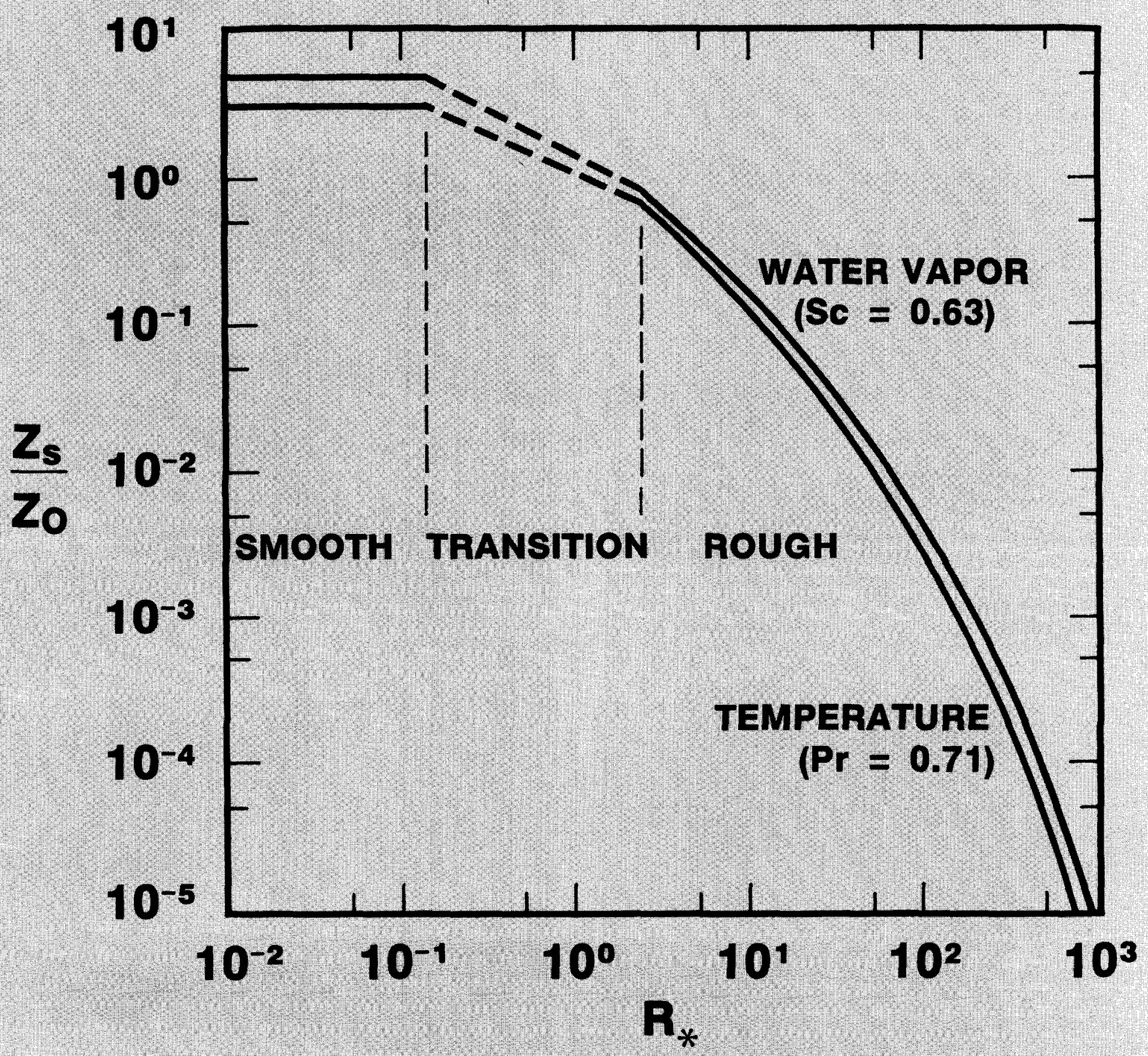




\section{CRREL Report 86-9}

September 1986

\section{A theory for the scalar roughness and the scalar transfer coefficients over snow and sea ice}

Edgar L Andreas 
SECURITY Unclassified

\begin{tabular}{|c|c|}
\hline REPORT DOCUMENTATION PAGE & $\begin{array}{l}\text { READ INSTRUCTIONS } \\
\text { BEFORE COMPLETING FORM }\end{array}$ \\
\hline $\begin{array}{l}\text { 1. REPORT NUMBER } \\
\text { CRREL Report } 86-9\end{array}$ & 3. RECIPIENT'S CATALOG NUMBER \\
\hline $\begin{array}{l}\text { 4. TITLE (and Subtile) } \\
\text { A THEORY FOR THE SCALAR ROUGHNESS AND } \\
\text { THE SCALAR TRANSFER COEFFICIENTS OVER } \\
\text { SNOW AND SEA ICE }\end{array}$ & 6. PERFORMING ORG. REPORT NLMBER \\
\hline $\begin{array}{l}\text { 7. AUTHOR(a) } \\
\text { Edgar L Andreas }\end{array}$ & 8. CONTRACT OR GRANT NUMBER(s) \\
\hline $\begin{array}{l}\text { 9. PERFORMING ORGANIZATION NAME ANO ADDRESS } \\
\text { U.S. Army Cold Regions Research and } \\
\text { Engineering Laboratory } \\
\text { Hanover, New Hampshire } 03755-1290\end{array}$ & $\begin{array}{l}\text { 10. PROGRAMELEMENT. PROJECT. TASK } \\
\text { AREA \& WORK UNIT NUMAERS } \\
\text { DA Project } 4 \text { A } 161102 \text { AT24 } \\
\text { Task FS, Work Unit } 002\end{array}$ \\
\hline \multirow{2}{*}{$\begin{array}{l}\text { 11. CONTROLLING OFFICE NAME AND ADDRESS } \\
\text { Office of the Chief of Engineers } \\
\text { Washington, D.C. } 20314-1000\end{array}$} & $\begin{array}{l}\text { 12. REPORT DATE } \\
\text { Septem ber } 1986\end{array}$ \\
\hline & $\begin{array}{l}\text { 13. NUMBER OF PAGES } \\
26\end{array}$ \\
\hline \multirow{2}{*}{ 14. MONITORING AGENCY NAME a ADDRESS(if different from Controlling Offico) } & $\begin{array}{l}\text { 5. SECURITY CLASS. (ot this roport) } \\
\text { Unclassified }\end{array}$ \\
\hline & $\begin{array}{l}\text { 15a. DECLASSIFICATION DOWNGRADING } \\
\text { SCHEDULE }\end{array}$ \\
\hline
\end{tabular}

16. DISTRIBUTION STATEMENT (ot this Report)

Approved for public release; distribution is unlimited.

17. DISTRIBUTION STATEMENT (of the abstract ontered in Block 20, if different from Report)

18. SUPPLEMENTARY NOTES

19. KEY WORDS (Continue on reverse side if nacessary and identlfy by block number)

Heat and moisture exchange

Roughness lengths

Surface processes

Sea ice

Turbulence

Snow

20. ABSTRACT (Contine on rever at aidie if neceveary and Identify by block number)

The bulk aerodynamic transfer coefficients for sensible $\left(C_{H}\right)$ and latent $\left(C_{E}\right)$ heat over snow and sea ice surfaces are necessary for accurately modeling the surface energy budget but are very difficult to measure. This report therefore presents a theory that predicts $C_{H}$ and $C_{E}$ as functions of the wind speed and a surface roughness parameter. The crux of the model is establishing the interfacial sublayer profiles of the scalars, temperature and wate vapor, over aerodynamically smooth and rough surfaces. These interfacial sublayer profiles are derived from a surface-renewal model in which turbulent eddies continually sweep

DD, FORM 1473 EDITION OF I NOV 55 IS OBSOLETE

Unclassified SECURITY CLASSIFICATION OF THIS PASE (Whon Data Entered) 


\section{Abstract (cont'd).}

down to the surface, transfer scalar contaminants across the interface by molecular diffusion, and then burst away. Matching the interfacial sublayer profiles with the usual semilogarithmic inertial sublayer profiles yields the roughness lengths for temperature and water vapor. With these and a model for the drag coefficient over snow and sea ice based on actual measurements, the transfer coefficients are predicted. $C_{E}$ is always a few percent larger than $C_{H}$. Both decrease monotonically with increasing wind speed for speeds above $1 \mathrm{~m} / \mathrm{s}$, and both increase at all wind speeds as the surface gets rougher. Both, nevertheless, are almost always between $1.0 \times 10^{-3}$ and $1.5 \times 10^{-3}$. 


\section{PREFACE}

This report was prepared by Dr. Edgar L Andreas, Physicist, of the Snow and Ice Branch, Research Division, U.S. Army Cold Regions Research and Engineering Laboratory. The work was supported by the Office of the Chief of Engineers, DA Project 4A161102AT24, Research in Snow, Ice and Frozen Ground; Task FS, Fire Support; Work Unit 002, Winter Surface Boundary Layer Physics.

The author thanks Brett Murphy for help with computing, William Bates for drafting the figures, Mark Hardenberg for editorial assistance, and Dr. V.J. Lunardini and Dr. Y.-C. Yen for reviewing the manuscript.

The contents of this report are not to be used for advertising or promotional purposes. Citation of brand names does not constitute an official endorsement or approval of the use of such commercial products. 


\section{CONTENTS}

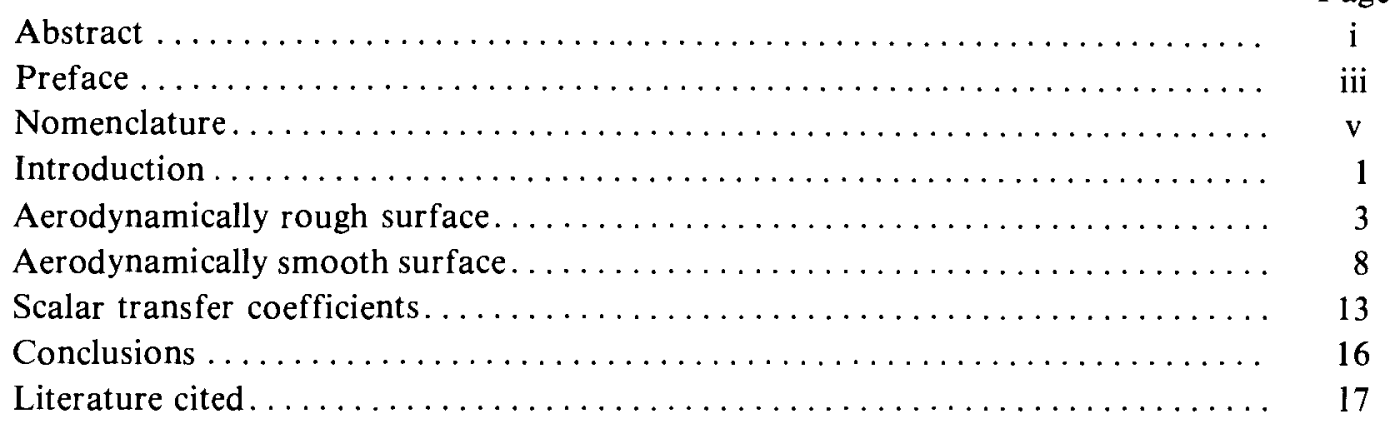

Preface $\ldots \ldots \ldots \ldots \ldots \ldots \ldots \ldots \ldots \ldots \ldots \ldots \ldots \ldots \ldots \ldots \ldots \ldots \ldots \ldots \ldots \ldots$ iii

Nomenclature $\ldots \ldots \ldots \ldots \ldots \ldots \ldots \ldots \ldots \ldots \ldots \ldots \ldots \ldots \ldots \ldots \ldots$

Introduction $\ldots \ldots \ldots \ldots \ldots \ldots \ldots \ldots \ldots \ldots \ldots \ldots \ldots \ldots \ldots \ldots \ldots$

Aerodynamically rough surface $\ldots \ldots \ldots \ldots \ldots \ldots \ldots \ldots \ldots \ldots \ldots \ldots \ldots \ldots \ldots$

Aerodynamically smooth surface $\ldots \ldots \ldots \ldots \ldots \ldots \ldots \ldots \ldots \ldots \ldots \ldots \ldots \ldots$

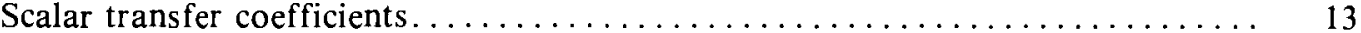

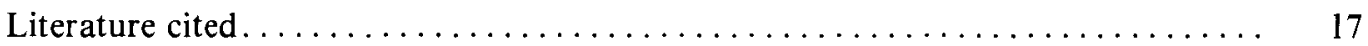

\section{ILLUSTRATIONS}

\section{Figure}

1. Matching height over an aerodynamically rough surface as a function of rough-

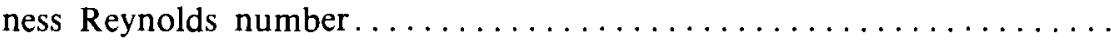

2. Matching of interfacial and inertial sublayer profiles of temperature and water vapor over an aerodynamically rough surface $\ldots \ldots \ldots \ldots \ldots \ldots \ldots$

3. Model predictions for an aerodynamically rough surface compared with measured scalar roughness lengths for water vapor, thorium-B and camphor ...

4. Model predictions for an aerodynamically rough surface compared with the experimental data of Dipprey and Sabersky (1963) . . . . . . . . . . .

5. Nondimensional matching height over an aerodynamically smooth surface as a

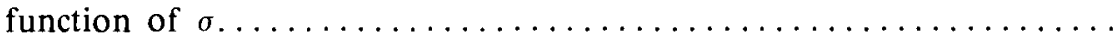

6. Matching of interfacial and inertial sublayer profiles of temperature and water vapor over an aerodynamically smooth surface $\ldots \ldots \ldots \ldots \ldots \ldots \ldots$

7. Current model predictions for an aerodynamically smooth surface compared with measured scalar roughness lengths for water vapor, thorium-B and heat, and with models by Brutsaert (1975b) and von Kármán (Goldstein

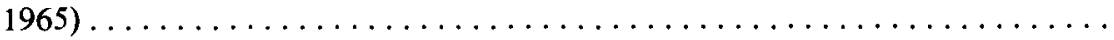

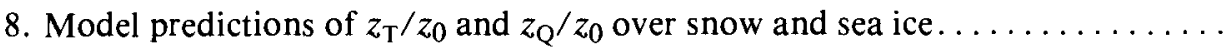

9. Bulk transfer coefficients for sensible and latent heat over snow or sea ice as a function of the rms surface roughness (in centimetres) and the 10-m wind speed . . . . . . . . . . . . . . . . . . . .

\section{TABLE}

Table

1. Values of the coefficients in the polynomials that predict $z_{\mathrm{s}} / z_{0}$ for temperature

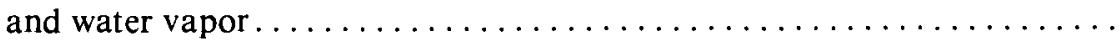




\section{NOMENCLATURE}

$A \quad \alpha_{\mathrm{H}} k G \operatorname{Pr}^{1 / 2} R_{*}^{1 / 4}$, a parameter in the equations modeling flow over a rough surface

a $\quad 10$, a constant that relates eddy contact time to distance traveled

$b_{0}, b_{1}, b_{2}$ Coefficients of the polynomials that predict $z_{\mathrm{T}} / z_{0}$ and $z_{\mathrm{Q}} / z_{0}$ as functions of roughness Reynolds number

$C_{\mathrm{D}} \quad$ Drag coefficient at neutral stability

$C_{\mathrm{E}} \quad$ Bulk transfer coefficient for latent heat at neutral stability

$C_{\mathrm{H}} \quad$ Bulk transfer coefficient for sensible heat at neutral stability

$c_{\mathrm{p}} \quad$ Specific heat of air at constant pressure

$D \quad$ Molecular diffusivity of heat

$D_{\mathrm{w}} \quad$ Molecular diffusivity of water vapor

$G \quad 5.6$, a constant that relates the Kolmogorov time scale to $t_{\mathrm{r}}$

$h \quad$ Height at which inertial and interfacial sublayer profiles match

$H_{\mathrm{L}} \quad$ Latent heat flux

$H_{\mathrm{s}} \quad$ Sensible heat flux

$K \quad$ A function of $\eta_{\mathrm{s}}$, defined by eq 49

$k \quad 0.4$, von Kármán's constant

$K_{\mathrm{e}} \quad$ Turbulent diffusivity of water vapor at neutral stability

$K_{\mathrm{H}} \quad$ Turbulent diffusivity of heat at neutral stability

$K_{\mathrm{M}} \quad$ Turbulent diffusivity of momentum at neutral stability

$L_{\mathrm{s}} \quad$ Latent heat of sublimation of ice

$\operatorname{Pr} \quad v / D$, Prandtl number

$Q \quad$ Water vapor density

$Q_{\mathrm{r}} \quad$ Water vapor density at an arbitrary reference height $r$

$Q_{0} \quad$ Water vapor density at the surface

$q_{*} \quad-H_{\mathrm{L}} / L_{\mathrm{s}} u_{*}$

$r \quad$ Reference height

$R_{*} \quad u_{*} z_{0} / v$, roughness Reynolds number

$S \quad$ Average profile value of an arbitrary scalar

$S_{0} \quad$ Value of the arbitrary scalar at the surface

$s_{*} \quad$ Equivalent to $t_{*}$ or $q_{*}$ for the arbitrary scalar

Sc $\quad v / D_{\mathrm{w}}$, Schmidt number

$T \quad$ Potential temperature

$t \quad$ Time

$\bar{t} \quad$ Average eddy contact time over a smooth surface

$T_{\mathrm{b}} \quad$ Bulk temperature just above the interfacial sublayer

$T_{\mathrm{r}} \quad$ Potential temperature at an arbitrary reference level $r$

$t_{\mathrm{r}} \quad G^{2}\left(z_{0} v / u_{\star}\right)^{1 / 2}$, fundamental eddy time scale over a rough surface

$t_{\mathrm{s}} \quad 85 v / u_{*}^{2}$, fundamental eddy time scale over a smooth surface

$T_{0} \quad$ Surface temperature

$t_{*} \quad-H_{\mathrm{s}} / \varrho c_{\mathrm{p}} u_{*}$ 


$\begin{array}{ll}U & \text { Longitudinal velocity } \\ U_{\mathrm{r}} & \text { Velocity at an arbitrary reference height } r \\ U_{10} & \text { Velocity at a reference level of } 10 \mathrm{~m} \\ u_{*} & (\tau / \varrho)^{1 / 2}, \text { friction velocity } \\ x & \text { Downwind distance } \\ x_{0} & \text { Distance over which an eddy remains in contact with a smooth surface } \\ z & \text { Height } \\ z_{\mathrm{Q}} & \text { Roughness length for water vapor } \\ z_{\mathrm{S}} & \text { Roughness length for an arbitrary scalar } \\ z_{\mathrm{T}} & \text { Roughness length for temperature } \\ z_{0} & \text { Roughness length for velocity } \\ \alpha_{\mathrm{E}} & K_{\mathrm{E}} / K_{\mathrm{M}}, \text { inverse of the turbulent Schmidt number } \\ \alpha_{\mathrm{H}} & K_{\mathrm{H}} / K_{\mathrm{M}}, \text { inverse of the turbulent Prandtl number } \\ \beta & \text { Multiplicative constant in Charnock's (1955) equation } \\ \delta_{\mathrm{T}} & \left(D t_{\mathrm{r}}\right)^{1 / 2}, \text { a fundamental length scale for flow over a rough surface } \\ \epsilon & \text { Dissipation rate of turbulent kinetic energy } \\ \zeta & z / \delta_{\mathrm{T}}, \text { nondimensional height over a rough surface } \\ \zeta & h / \delta_{\mathrm{T}}, \text { nondimensional matching height over a rough surface } \\ \eta & u_{*}^{2} z^{3 / 9} v D x, \text { nondimensional variable characterizing flow over a smooth sur- } \\ \eta_{\mathrm{S}} & \text { face } \\ \eta_{\mathrm{S}} & u_{*} z^{3 / 9} a v D t_{\mathrm{s}}, \text { nondimensional height over a smooth surface } \\ \eta_{0} & u_{*} h^{3} / 9 a v D t_{\mathrm{s}}, \text { nondimensional matching height over a smooth surface } \\ v & u_{*} z^{3 / 9} v D x_{0}, \text { another form of the nondimensional height over a smooth sur- } \\ \phi_{\mathrm{r}} & \text { Kace } \\ \xi & \text { Kinematic viscosity of air } \\ \varrho & \text { Root-mean-square surface elevation in centimetres } \\ \sigma & \text { Density of air } \\ & \text { Ratio of kinematic viscosity to molecular diffusivity; equivalent to Pr for heat } \\ \phi_{\mathrm{S}} & \text { Distribution function for eddy contact time over a smooth surface } \\ & \end{array}$




\title{
A Theory for the Scalar Roughness and the Scalar Transfer Coefficients Over Snow and Sea Ice
}

\author{
EDGAR L ANDREAS
}

\section{INTRODUCTION}

In the atmospheric surface layer at neutral stability, the velocity $(U)$, potential temperature $(T)$, and water vapor density $(Q)$ profiles have the familiar, semi-logarithmic form,

$$
\begin{aligned}
& \frac{U(z)}{u_{*}}=k^{-1} \ln \left(z / z_{0}\right), \\
& \frac{T(z)-T_{0}}{t_{*}}=\left(\alpha_{\mathrm{H}} k\right)^{-1} \ln \left(z / z_{\mathrm{T}}\right), \\
& \frac{Q(z)-Q_{0}}{q_{*}}=\left(\alpha_{\mathrm{E}} k\right)^{-1} \ln \left(z / z_{\mathrm{Q}}\right)
\end{aligned}
$$

Here $z$ is the height above the surface; $k$ is von Kármán's constant $(0.4) ; T_{0}$ is the surface temperature; $Q_{0}$ is the water vapor density of air in saturation with a snow or sea ice surface at $T_{0}$; and $\alpha_{\mathrm{H}}\left(=K_{\mathrm{H}} / K_{\mathrm{M}}\right)$ and $\alpha_{\mathrm{E}}\left(=K_{\mathrm{E}} / K_{\mathrm{M}}\right)$ are the ratios of the scalar turbulent diffusivities, $K_{\mathrm{H}}$ and $K_{\mathrm{E}}$, to the turbulent diffusivity for momentum $K_{\mathrm{M}}$ (e.g., Dyer 1974). The $u_{*}, t_{*}$ and $q_{*}$ relate the profiles to the turbulent surface fluxes of momentum $(\tau)$ and sensible $\left(H_{\mathrm{s}}\right)$ and latent $\left(H_{\mathrm{L}}\right)$ heat:

$$
\begin{aligned}
& \tau=\varrho u_{*}^{2}, \\
& H_{\mathrm{s}}=-\varrho c_{\mathrm{p}} u_{*} t_{*}, \\
& H_{\mathrm{L}}=-L_{\mathrm{s}} u_{*} q_{*},
\end{aligned}
$$

where $\varrho=$ air density

$c_{\mathrm{p}}=$ specific heat of air at constant pressure

$L_{\mathrm{s}}=$ latent heat of sublimation of ice.

Equations 1-3 define the roughness lengths. $z_{0}$ is the familiar roughness length for wind speed; $z_{\mathrm{T}}$ and $z_{\mathrm{Q}}$ are the roughness lengths for temperature and water vapor-the so-called scalar roughness lengths. $z_{0}$ is the height at which the semi-logarithmic velocity profile extrapolates to $U=0$. Similarly, $z_{\mathrm{T}}$ and $z_{\mathrm{Q}}$ are the heights at which the semi-logarithmic temperature and water vapor profiles extrapolate to the surface values, $T_{0}$ and $Q_{0}$, respectively. All are fictitious levels since the semi-logarithmic profiles are not valid clear down to the roughness lengths. 
Knowing the roughness lengths is equivalent to knowing the bulk-aerodynamic transfer coefficients for momentum ( $C_{\mathrm{D}}$, the drag coefficient) and for the scalars, sensible $\left(C_{\mathrm{H}}\right)$ and latent $\left(C_{\mathrm{E}}\right)$ heat. After specifying a reference height $r$ (henceforth taken as $10 \mathrm{~m}$ ) to be the level where average values of wind speed $\left(U_{\mathrm{r}}\right)$, temperature $\left(T_{\mathrm{r}}\right)$, and humidity $\left(Q_{\mathrm{r}}\right)$ are measured, we define these transfer coefficients as

$$
\begin{aligned}
& \tau=\varrho C_{\mathrm{D}} U_{\mathrm{r}}^{2}, \\
& H_{\mathrm{s}}=\varrho c_{\mathrm{p}} C_{\mathrm{H}} U_{\mathrm{r}}\left(T_{0}-T_{\mathrm{r}}\right), \\
& H_{\mathrm{L}}=L_{\mathrm{s}} C_{\mathrm{E}} U_{\mathrm{r}}\left(Q_{0}-Q_{\mathrm{r}}\right) .
\end{aligned}
$$

For neutral stability eq $1-6$, in turn, relate these coefficients to the roughness lengths:

$$
\begin{aligned}
& C_{\mathrm{D}}=\frac{k^{2}}{\left[\ln \left(r / z_{0}\right)\right]^{2}}, \\
& C_{\mathrm{H}}=\frac{\alpha_{\mathrm{H}} k C_{\mathrm{D}}^{1 / 2}}{k C_{\mathrm{D}}^{1 / 2}-\ln \left(z_{\mathrm{T}} / z_{0}\right)}, \\
& C_{\mathrm{E}}=\frac{\alpha_{\mathrm{E}} k C_{\mathrm{D}}^{1 / 2}}{k C_{\mathrm{D}}^{-1 / 2}-\ln \left(z_{\mathrm{Q}} / z_{0}\right)} .
\end{aligned}
$$

Since correcting the transfer coefficients for stability effects is straightforward (e.g., Deardorff 1968, Large and Pond 1982), from here on all of my references to transfer coefficients will be to these neutral-stability ones. Clearly, from eq 10-12, $C_{\mathrm{H}}=C_{\mathrm{D}}$ only when $z_{\mathrm{T}}=z_{0}$ and $\alpha_{\mathrm{H}}=1$; and $C_{\mathrm{E}}=C_{\mathrm{D}}$ only when $z_{\mathrm{Q}}=z_{0}$ and $\alpha_{\mathrm{E}}=1$. I will show shortly that, contrary to the common assumption (e.g., Paulson 1970, Businger et al. 1971, Lettau 1979), $z_{\mathrm{T}}$ and $z_{\mathrm{Q}}$ rarely equal $z_{0}$.

A typical goal of micrometerology is to find $C_{\mathrm{D}}, C_{\mathrm{H}}$ and $C_{\mathrm{E}}$ or, equivalently, $z_{0}, z_{\mathrm{T}}$ and $z_{\mathrm{Q}}$. These are fairly well known over the ocean but are still only poorly known over most other horizontally homogeneous surfaces. In particular, only $C_{\mathrm{D}}$ is well known over sea ice. The extensive set of $C_{\mathrm{D}}$ values that Banke et al. (1980) reported show that over sea ice $C_{\mathrm{D}}$ is an increasing function of the surface roughness. The roughness parameter here is the root-meansquare (rms) surface elevation along a line parallel to the wind direction and should not be confused with the roughness length $z_{0}$. Leavitt et al. (1977) also found that $C_{\mathrm{D}}$ increased as the sea ice surface got rougher. Arya $(1973,1975)$ had theoretically predicted this increase in $C_{\mathrm{D}}$ with roughness, showing it to be a consequence of the form drag.

I know, however, of only two published attempts to measure $C_{\mathrm{H}}$ and $C_{\mathrm{E}}$ over snow or sea ice, those by Hicks and Martin (1972) over snow-covered Lake Mendota and by Thorpe et al. (1973) in the Beaufort Sea and in Robeson Channel. And the results are inconclusive. Hicks and Martin (1972) found $C_{\mathrm{H}}=0.9 \times 10^{-3}$ and $C_{\mathrm{E}}=2.5 \times 10^{-3}$, while Thorpe et al. (1973) reported $C_{\mathrm{H}}=1.2 \times 10^{-3}$ and $C_{\mathrm{E}}=0.55 \times 10^{-3}$. That is, in one case $C_{\mathrm{H}} / C_{\mathrm{E}}=0.4$, and in the other $C_{\mathrm{H}} / C_{\mathrm{E}}=2.2$. With only these few, contradictory values and without an adequate theory from which to estimate $C_{\mathrm{H}}$ and $C_{\mathrm{E}}$ in the absence of experimental values, sea ice modelers have had to rely on intuition or convention. Most (e.g., Parkinson and Washington 1979, Hibler 1980) have followed Maykut (1978) and assumed that $C_{\mathrm{H}}$ and $C_{\mathrm{E}}$ are constantboth equal to $1.75 \times 10^{-3}$. But eq 11 and 12 imply that $C_{\mathrm{H}}$ and $C_{\mathrm{E}}$ are not constant; they depend on the characteristics of the surface and on the wind speed, since $C_{\mathrm{D}}$ depends on the surface characteristics. Andreas and Ackley (1982) evidently were the first to point this out. 
In this paper I will present a theoretical model for predicting $C_{\mathrm{H}}$ and $C_{\mathrm{E}}$ over snow and sea ice that relies on the empirical dependence of $C_{\mathrm{D}}$ on surface roughness reported by Banke et al. (1980). From eq 11 and 12 it is clear that to predict $C_{\mathrm{H}}$ and $C_{\mathrm{E}} \mathrm{I}$ must also find $z_{\mathrm{T}} / z_{0}$ and $z_{\mathrm{Q}} / z_{0}$. To do this I derive the scalar profiles in the interfacial sublayer over both aerodynamically rough and aerodynamically smooth surfaces. Matching these to the semi-logarithmic or inertial sublayer (Tennekes and Lumley 1972, p. 147) profiles (eq 2 and 3), I then solve for the scalar roughness. I treat snow and sea ice with the same model because sea ice is generally snow covered; the two surfaces are therefore aerodynamically similar.

\section{AERODYNAMICALLY ROUGH SURFACE}

With the ratio of kinematic viscosity to molecular diffusivity ( $\sigma$ ), the roughness Reynolds number $R_{*}=u_{*} z_{0} / v$ customarily parameterizes wall-bounded shear flows. Although two flows may have different velocity or length scales or different kinematic viscosities $(v)$, they are dynamically similar if their roughness Reynolds numbers and their $\sigma$ values are the same. Three dynamic regimes are possible, each characterized by a different $R_{*}$ range (e.g., Businger 1973). If $R_{*} \leq \mathrm{e}^{-2}=0.135$, the surface roughness elements are imbedded in the viscous sublayer and the surface is aerodynamically smooth. If $R_{*} \geq 2.5$, the roughness elements poke through the viscous sublayer and the surface is aerodynamically rough. For $0.135<R$ * $<2.5$, the surface is in transition.

Brutsaert (1975a) and Liu et al. (1979) based models of the turbulent transfer over aerodynamically rough surfaces on a surface-renewal model (Danckwerts 1970, p. 100). Small eddies continually sweep into the interfacial sublayer, remain in contact with the surface for a short time, transferring heat and moisture by molecular diffusion, and then finally burst upward ahead of inrushing new eddies. Grass (1971) suggested that while the eddies are in contact with the surface, they may be stagnant-trapped by the roughness elements. Brutsaert (1975a) thus assumed that over a rough surface the interfacial transfer of scalar properties is strictly a diffusion process. That is, using temperature as an example,

$$
\frac{\partial T}{\partial t}=D \frac{\partial^{2} T}{\partial z^{2}}
$$

where $t$ is time. In eq 13 and in all that follow, we could use water vapor or any other scalar that obeys the same conservation equation as temperature (Hill 1978); the only changes would be in the molecular diffusivity $D$ and in the other thermodynamic constants, such as the $\alpha$ 's or $c_{\mathrm{p}}$ and $L_{\mathrm{v}}$. The boundary conditions on eq 13 are

$$
\begin{array}{lll}
T=T_{\mathrm{b}} & \text { for } z>0, & t=0, \\
T=T_{\mathrm{b}} & \text { for large } z, & t>0, \\
T=T_{0} & \text { for } z=0, & t>0,
\end{array}
$$

where $T_{\mathrm{b}}$ is the "bulk" temperature above the interfacial sublayer. Many standard texts show how to solve eq 13 with the boundary conditions of eq 14 (e.g., Duff and Naylor 1966, p. 118); the solution is

$$
\left.T(z, t)=\left(T_{0^{-}} T_{\mathrm{b}}\right) \operatorname{erfc} \mid \frac{z}{2(D t)^{1 / 2}}\right\rceil+T_{\mathrm{b}}
$$

where erfc is one minus the error function, erf (Abramowitz and Stegun 1965, p. 297). 
Equation 15 models the diffusion into a single eddy. Because eddies continually sweep over the surface, we must integrate in time to find the average interfacial sublayer temperature profile. Brutsaert (1975a) and Liu and Businger (1975) used Danckwerts' (1951) distribution function,

$$
\phi_{\mathrm{r}}(t)=t_{\mathrm{r}}^{-1} \exp \left(-t / t_{\mathrm{r}}\right), \quad t>0
$$

to model the fraction of surface area that has had eddies in contact for a time $t$. Here $t_{\mathrm{r}}$ is a time scale yet to be specified. The time-averaged temperature profile is thus

$$
T(z)=\int_{0}^{\infty} T(z, t) \phi_{\mathrm{r}}(t) d t
$$

Abramowitz and Stegun (1965, p. 303) show how to integrate the error function in eq 15; the solution of eq 17 is thus

$$
T(z)=T_{0}-\left(T_{0}-T_{\mathrm{b}}\right)\left[1-\exp \left(-z / \delta_{\mathrm{T}}\right)\right],
$$

where

$$
\delta_{\mathrm{T}}=\left(D t_{\mathrm{r}}\right)^{1 / 2}
$$

Khundzhua and Andreyev (1974) verified eq 18 experimentally in the aqueous sublayer in the Black Sea and related the length scale $\delta_{\mathrm{T}}$ to the sensible heat flux. For air this relation is

$$
\delta_{\mathrm{T}}=\varrho c_{\mathrm{p}} D\left(T_{0^{-}} T_{\mathrm{b}}\right) / H_{\mathrm{s}}
$$

Actually, eq 20 is a necessary consequence of eq $18 . H_{s}$ is related to the temperature gradient evaluated at the surface by

$$
H_{\mathrm{s}}=-\left.\varrho c_{\mathrm{p}} D \frac{\partial T}{\partial z}\right|_{z=0}
$$

But from eq $18, \partial T /\left.\partial z\right|_{z=0}$ is simply $\left(T_{\mathrm{b}}-T_{0}\right) / \delta_{\mathrm{T}}$; eq 20 thus follows from eq 21 .

Substituting eq 5 for $H_{\mathrm{s}}$ in eq 20, we can write

$$
T_{0}-T_{\mathrm{b}}=-u_{*} t_{*} \delta_{\mathrm{T}} / D
$$

Substituting this into eq 18 yields a form for the temperature profile in the interfacial sublayer that is compatible with the inertial sublayer profile,

$$
\frac{T(z)-T_{0}}{t_{*}}=\left(u_{*} \delta_{\mathrm{T}} / D\right)[1-\exp (-\zeta)]
$$

Here $\zeta=z / \delta_{\mathrm{T}}$.

Brutsaert (1975a) and Liu et al. (1979) assumed that the time scale $t_{\mathrm{r}}$ in $\delta_{\mathrm{T}}$, eq 19, is proportional to the Kolmogorov time scale $(v / \epsilon)^{1 / 2}$, where $\epsilon$ is the dissipation rate of turbulent kinetic energy. Formalizing this assumption by defining a proportionality constant $G$ and setting $\epsilon=u_{*}^{3} / z_{0}$ (Liu et al. 1979), we have 


$$
t_{\mathrm{r}}=G^{2}\left(z_{0} v / u_{*}^{3}\right)^{1 / 2},
$$

or

$$
\delta_{\mathrm{T}} / z_{0}=G \operatorname{Pr}^{-1 / 2} R_{*}^{-3 / 4}
$$

where $\operatorname{Pr}=v / D$ is the Prandtl number. Liu et al. (1979) estimated $G=9.3$ on the basis of data reported by Mangarella et al. (1973) for flow over wind waves. Since snow or sea ice surfaces are less compliant than water, this value of $G$ may not be appropriate. In fact, in evaluating $G$, Liu et al. (1979) also considered data reported by Chamberlain (1968) that imply $G=5.6$ for flows over various solid surfaces. My model, with this $G$ value, fits data collected over various solid surfaces much better than with $G=9.3$. Evidently, the proportionality constant in eq 24 and 25 depends on whether the surface is firm or compliant.

With eq 25 we can now simultaneously solve eq 2 and 23 to find $z_{\mathrm{T}}$. This is where I diverge from Brutsaert (1975a). I will simply match both the temperature profiles and their first derivatives at $z=h$. The temperature and the heat flux will therefore both be continuous from the interfacial to the inertial sublayer. With these profile and first-derivative equations, I can find the two unknowns $h$ and $z_{\mathrm{T}}$. Brutsaert (1975a) never computed the interfacial sublayer profile; instead he solved for $z_{\mathrm{T}}$ by matching the interfacial and inertial sublayer fluxes at the arbitrary level $h=7.39 z_{0}$. Although they do not say explicitly, Liu et al. (1979) used the method of solution that I am proposing. They, however, set $G=9.3$ and $\alpha_{H}=\alpha_{E}=1.14$, while I use $G=5.6$ and $\alpha_{\mathrm{H}}=\alpha_{\mathrm{E}}=1.0$.

Matching the profiles eq 2 and 23 at $z=h$ gives

$$
\ln \hat{\zeta}-\ln \left(z_{0} / \delta_{\mathrm{T}}\right)-\ln \left(z_{\mathrm{T}} / z_{0}\right)=A[1-\exp (-\hat{\zeta})]
$$

where

$$
\hat{\zeta}=h / \delta_{\mathrm{T}},
$$

and

$$
A=\alpha_{\mathrm{H}} k G \operatorname{Pr}^{1 / 2} R_{*}^{1 / 4}
$$

Matching the first derivatives at $\hat{\zeta}$ yields

$$
\hat{\zeta} \exp (-\hat{\zeta})=A^{-1}
$$

I do not need to worry here or in eq 26 about the stability of the atmospheric surface layer and its effects on the inertial sublayer profiles. We will see that the matching level is well below the region where atmospheric stability affects the semi-logarithmic profiles (Bradley 1972). Notice, eq 29 has a solution only for $A>2.72$. Substituting it into eq 26 gives a formal expression for $z_{\mathrm{T}} / z_{0}$,

$$
z_{\mathrm{T}} / z_{0}=\hat{\zeta}\left(\delta_{\mathrm{T}} / z_{0}\right) \exp \left[\hat{\zeta}^{-1}-A\right]
$$

Here $A$ and $\delta_{\mathrm{T}}$ are functions only of $\operatorname{Pr}$ and $R_{*}$. We solve for $\hat{\zeta}$ by using Newton's method to find the zeroes in eq 29 as functions of $\operatorname{Pr}$ and $R_{*}$. Figure 1 shows $h / z_{0}=\left(\hat{\zeta} \delta_{\mathrm{T}} / z_{0}\right)$ for both temperature and water vapor when $R_{*}=10$. The values are much smaller than the constant that Brutsaert (1975a) used. He chose $h=7.39 z_{0}$ because this is approximately the 

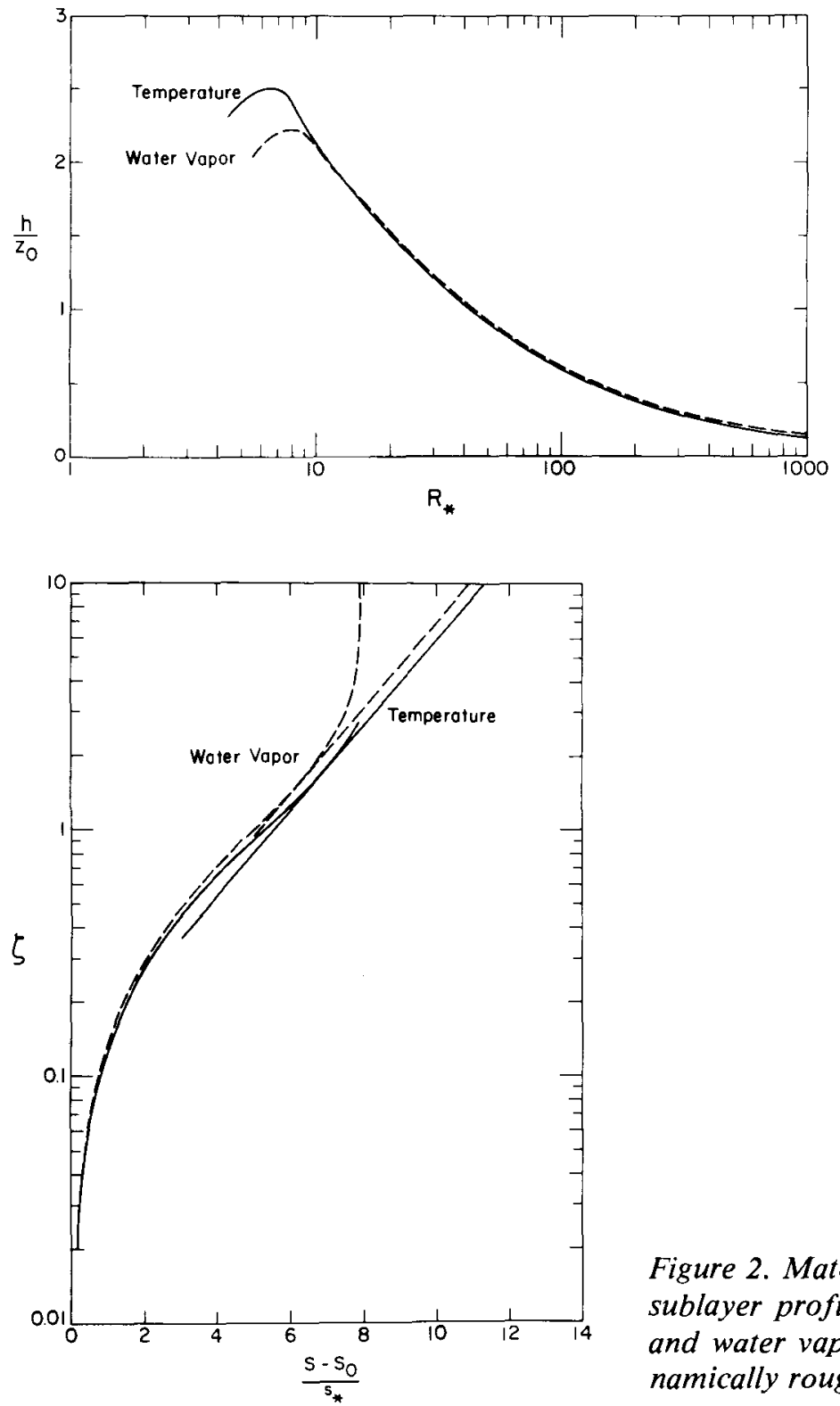

Figure 1. Matching height over an aerodynamically rough surface as a function of roughness Reynolds number. For temperature, $\sigma=$ $0.71 ;$ for water vapor, $\sigma=0.63$.

Figure 2. Matching of interfacial and inertial sublayer profiles of temperature $(\sigma=0.71)$ and water vapor $(\sigma=0.63)$ over an aerodynamically rough surface for $\mathrm{R}_{*}=10$.

height of the roughness elements. By implying that the roughness elements protrude above the interfacial sublayer, Figure 1 is, thus, consistent with our conceptual model of molecular diffusion into stagnant eddies.

Figure 2 shows the transition of temperature and water vapor profiles from the interfacial to the inertial sublayer. Both the profiles and their first derivatives are continuous. The vertical fluxes of sensible and latent heat are, therefore, also continuous.

Figure 3 compares predictions of my model for the scalar roughness, $z_{\mathrm{s}}$, with experimental data from Owen and Thomson (1963) and Chamberlain $(1966,1968)$. All the data sets are from wind tunnel measurements and represent three different $\sigma$ values. Chamberlain (1966) studied water vapor transfer over toweling and artificial grass $\left(\sigma=0.62\right.$ at $\left.\sim 20^{\circ} \mathrm{C}\right)$. Because the grass, however, had a roughness length of $1.0 \mathrm{~cm}-$ much larger than that typical of snow or sea ice (Untersteiner and Badgley 1965, Banke et al. 1980, Schmidt 1982)-and roughness elements unlike those of snow or sea ice, I have not included those data. Chamberlain (1968) collected his thorium-B $(\sigma=2.78)$ and water vapor data over a host of two- and three- 


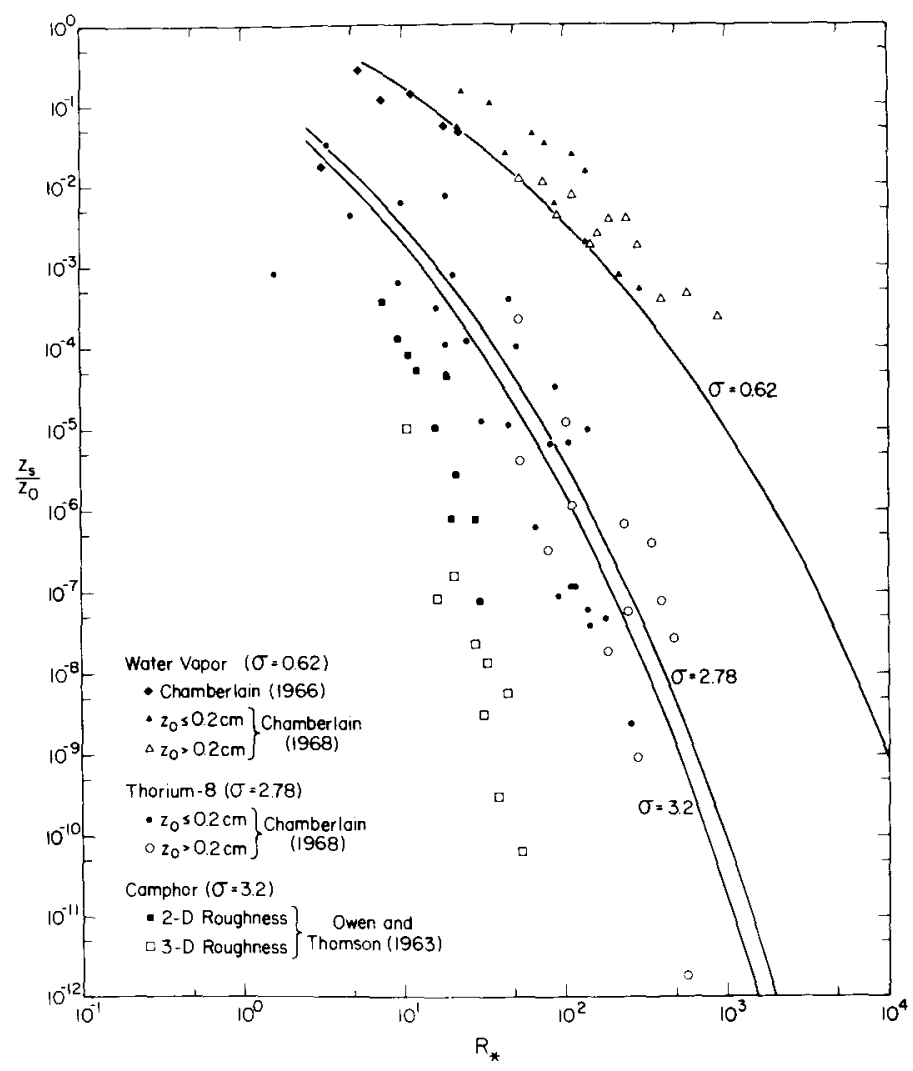

Figure 3. Model predictions for an aerodynamically rough surface compared with measured scalar roughness lengths for water vapor, thorium-B and camphor.

dimensional roughness elements, some with roughness lengths as large as $0.6 \mathrm{~cm}$. In the figure I have indicated the data for surfaces with $z_{0}>0.2 \mathrm{~cm}$-roughly the maximum sea ice roughness that Banke et al. (1980) reported. No systematic difference between large and small roughness lengths is evident, however. Owen and Thomson (1963) looked at the transfer of camphor ( $\sigma=3.2$ ) over glass surfaces with two- and three-dimensional roughness.

Measuring $z_{\mathrm{s}} / z_{0}$ is difficult under any circumstances-even in a wind tunnel-because, as eq 1 and 2 show with temperature for example, we have to know $u_{*}, t_{*}$ and $z_{0}$. Chamberlain (1968) explained that his $z_{0}$ values alone may have been in error by $50 \%$. The scatter of the data in Figure 3 is, thus, not surprising. In view of this uncertainty, the model predictions are quite good. The model reproduces the $R_{*}$-dependence at constant $\sigma$ very well and has $z_{\mathrm{s}} / z_{0}$ decreasing with increasing $\sigma$, as the data do. Only the $z_{\mathrm{s}} / z_{0}$ data from Owen and Thomson (1963) deviate significantly from model predictions. I can only speculate that significant measurement errors crept into their results. For example, Owen and Thomson (1963) determined the camphor flux by weighing a test section of the floor of their wind tunnel before and after each experimental run. The 7-cm-square glass test section must have been at least $100 \mathrm{~g}$, but the typical difference in camphor coating before and after each of their runs was only $0.1 \mathrm{~g}$. Their flux measurement, therefore, likely had low precision. Secondly, as camphor was subliming from the floor of the wind tunnel during a run, the $z_{0}$ value may have been changing. 


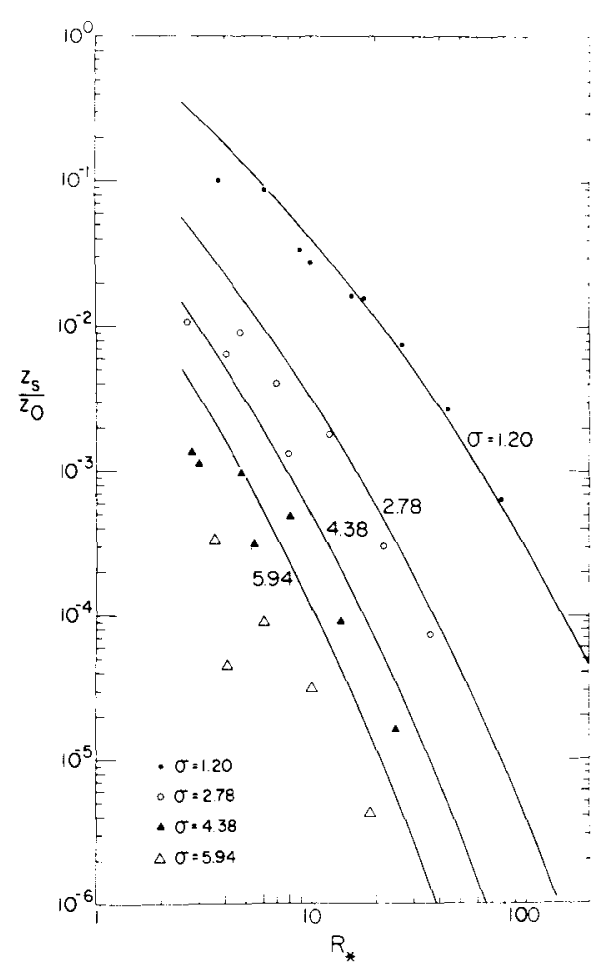

Figure 4. Model predictions for an aerodynamically rough surface compared with the experimental data of Dipprey and Sabersky (1963).

Figure 4 compares model predictions of $z_{\mathrm{s}} / z_{0}$ with the data of Dipprey and Sabersky (1963), who investigated heat transfer in water-filled pipes. Pipe flow may not seem to be a good experimental model for flow in the atmospheric surface layer, but the two are, in fact, mathematically equivalent. Flow in pipes is characterized by a viscous sublayer near the wall and a semi-logarithmic inertial sublayer further from the wall (Schlichting 1968, p. 578; Tennekes and Lumley 1972, p. 149), just like my model for the atmospheric surface layer. Figure 4 confirms the validity of the comparison. Dipprey and Sabersky (1963) varied $\sigma$ by changing the water temperature; the model fits their data extremely well for $\sigma=1.20$ and reasonably well at the other $\sigma$ values. For all of the $\sigma$ values in the figure, the difference between the data and the model predictions tends to decrease as $R_{*}$ increases. This suggests some experimental imprecision at low flow rates. Nevertheless, as in Figure 3, the model does reproduce the general trends in the data. In summary, my model seems to be an adequate fit to the available data that are most representative of an aerodynamically rough snow or sea ice surface.

\section{AERODYNAMICALLY SMOOTH SURFACE}

Brutsaert (1975a) also modeled scalar transfer over an aerodynamically smooth surface by again postulating a surface-renewal mechanism. Over a smooth surface, however, an impinging eddy remains in motion; the transfer is thus governed by an advective diffusion model,

$$
U(z) \frac{\partial T}{\partial x}=D \frac{\partial^{2} T}{\partial z^{2}},
$$


where $U(z)$ is the velocity profile in the viscous sublayer. The boundary conditions on eq 31 are

$$
\begin{array}{lll}
T=T_{\mathrm{b}} & \text { for } z>0, & x=0, \\
T=T_{\mathrm{b}} & \text { for large } z, & x>0, \\
T=T_{0} & \text { for } z=0, & x>0 .
\end{array}
$$

In the viscous sublayer, $z u_{*} / v<5$,

$$
U(z)=u_{*}^{2} z / v
$$

(e.g., Monin and Yaglom 1971, p. 270; Brutsaert 1975a). On substituting eq 33 into eq 31 and making the change of variables

$$
\eta=\frac{u_{*}^{2}}{9 v D} \frac{z^{3}}{x}
$$

suggested by Kestin and Persen (1962), we get the equation

$$
(\eta+2 / 3) \frac{\partial T}{\partial \eta}+\eta \frac{\partial^{2} T}{\partial \eta^{2}}=0
$$

The solution that satisfies the boundary conditions is (Kestin and Persen 1962)

$$
T(\eta)=T_{0^{-}}\left(T_{0^{-}} T_{\mathrm{b}}\right) \frac{\gamma(1 / 3, \eta)}{\Gamma(1 / 3)}
$$

where $\Gamma$ is the gamma function and $\gamma$ is the incomplete gamma function (Abramowitz and Stegun 1965, p. 255 and 260, respectively). Although Brutsaert (1975a) posed eq 31 with the boundary conditions of eq 32, he solved only for $\partial T / \partial z$ at $z=0$.

We next impose the assumptions of the surface-renewal model-that the eddy is in contact with the surface only for $0 \leq x \leq x_{0}$. Averaging $T(\eta)$ over this distance yields

$$
T\left(z, x_{0}\right)=T_{0}-\frac{\left(T_{0}-T_{\mathrm{b}}\right)}{\Gamma(1 / 3)}\left[\gamma\left(1 / 3, \eta_{0}\right)+\eta_{0} \Gamma\left(-2 / 3, \eta_{0}\right)\right]
$$

where

$$
\Gamma\left(-2 / 3, \eta_{0}\right)=\Gamma(-2 / 3)-\gamma\left(-2 / 3, \eta_{0}\right)
$$

is another form of the incomplete gamma function, and

$$
\eta_{0}=\frac{u_{*}^{2}}{9 v D} \frac{z^{3}}{x_{0}}
$$

To remove the explicit dependence on $x_{0}$ in eq 37, we have to average over all possible values of $x_{0}$. Brutsaert (1975a) suggested setting

$$
x_{0}=a u_{*} t \text {, }
$$


where $a$ is a constant, and then using eq 16 for the distribution function of $t$. In other words, we would again have the integral eq 17, with eq 37 substituted for eq 15. If Brutsaert had attempted this integration, he would have found the integral infinite. The reason is that the distribution function (eq 16) is not the appropriate one over a smooth surface. The work of Kim et al. (1971) suggested that for smooth surfaces the eddy-contact time has the distribution

$$
\phi_{\mathrm{S}}(t)=\left(t / t_{\mathrm{S}}^{2}\right) \exp \left(-t / t_{\mathrm{S}}\right), \quad . \quad t>0,
$$

where $t_{\mathrm{S}}$ is a new time scale. The average contact time is thus $\bar{t}=2 t_{\mathrm{s}}$. In addition, from Figures 23 and 24 in Kim et al. (1971) I derived

$$
\bar{t}=170 v / u_{*}^{2}
$$

or

$$
t_{\mathrm{s}}=85 v / u_{*}^{2} .
$$

Notice, since $v / u_{*}$ is the appropriate scaling length in the viscous sublayer over a smooth surface (Tennekes and Lumley 1972, p. 152), $v / u_{*}^{2}$ is the only reasonable time scale there.

Substituting eq 37 and 41 into the time-averaging integral, eq 17, rearranging arguments a little, and defining

$$
\eta_{\mathrm{s}}=\frac{u_{*} z^{3}}{9 a v D t_{\mathrm{s}}}
$$

we derive an expression for the average profile in the interfacial sublayer,

$$
T(z)=T_{0}-\frac{\left(T_{0}-T_{\mathrm{b}}\right) \eta_{\mathrm{s}}^{2}}{\Gamma(1 / 3)} \int_{0}^{\infty}\left[\eta_{0}^{-1} \gamma\left(1 / 3, \eta_{0}\right)+\Gamma\left(-2 / 3, \eta_{0}\right)\right] \eta_{0}^{-2} \exp \left(-\eta_{\mathrm{s}} / \eta_{0}\right) d \eta_{0}
$$

The method of steepest descent (e.g., Dennery and Krzywicki 1967) is useful for approximating such difficult integrals; it yields

$$
\begin{aligned}
T(z)=T_{0}- & \frac{\left(T_{0}-T_{\mathrm{b}}\right)}{\Gamma(1 / 3)}\left\{0.960 \gamma\left(1 / 3, \eta_{\mathrm{s}} / 2\right)\right. \\
& \left.+1.383 \eta_{\mathrm{s}}\left[\gamma\left(1 / 3, \eta_{\mathrm{s}}\right)-\Gamma(1 / 3)+\eta_{\mathrm{s}}^{-2 / 3} \exp \left(-\eta_{\mathrm{s}}\right)\right]\right\}
\end{aligned}
$$

This, to my knowledge, is the first derivation of the interfacial sublayer profile of a scalar over an aerodynamically smooth surface that is based on surface-renewal concepts.

As with the rough-surface case, we have to eliminate $T_{b}$ in eq 46 to match the interfacial and inertial sublayer profiles. Again, we know how the surface flux is related to the profilesimply by eq 21 . Using this and substituting eq 43 for $t_{\mathrm{s}}$ in eq 46 we find

$$
T_{0}-T_{\mathrm{b}}=1.519(85 a)^{1 / 3} \operatorname{Pr}^{2 / 3} t_{*}
$$

Hence,

$$
T(z)=T_{0}+1.458(85 a)^{1 / 3} \operatorname{Pr}^{2 / 3} \cdot t_{*} K\left(\eta_{\mathrm{s}}\right),
$$

where 


$$
K\left(\eta_{\mathrm{s}}\right)=\Gamma(1 / 3)^{-1}\left\{\gamma\left(1 / 3, \eta_{\mathrm{s}} / 2\right)+1.44\left[\gamma\left(1 / 3, \eta_{\mathrm{s}}\right)-\Gamma(1 / 3)+\eta_{\mathrm{s}}^{-2 / 3} \exp \left(-\eta_{\mathrm{s}}\right)\right]\right\}
$$

Notice, with $t_{\mathrm{s}}$, eq 43 , substituted into $\eta_{\mathrm{s}}$, eq 44 , and recognizing that over a smooth surface

$$
z_{0}=\mathrm{e}^{-2} v / u_{*}
$$

(Tennekes and Lumley 1972, p. 157), $\eta_{\mathrm{s}}$ becomes

$$
\eta_{\mathrm{s}}=\frac{\mathrm{e}^{-6}}{9 \cdot 85 \cdot a} \operatorname{Pr}\left(\frac{z}{z_{0}}\right)^{3} \text {. }
$$

Matching the profiles at $z=h$ or at

$$
\hat{\eta}_{\mathrm{S}}=\frac{\mathrm{e}^{-6}}{9 \cdot 85 \cdot a} \operatorname{Pr}\left(\frac{h}{z_{0}}\right)^{3},
$$

we get

$$
1 / 3 \ln \hat{\eta}_{\mathrm{S}}+1 / 3 \ln \left(\frac{9 \cdot 85 \cdot a}{\mathrm{e}^{-6} \mathrm{Pr}}\right)-\ln \left(z_{\mathrm{T}} / z_{0}\right)=1.458 \alpha_{\mathrm{H}} k(85 a)^{1 / 3} \operatorname{Pr}^{2 / 3} K\left(\hat{\eta}_{\mathrm{S}}\right)
$$

And matching the slopes there, too,

$$
\begin{aligned}
1 / 3= & 1.458 \alpha_{\mathrm{H}} k(85 a)^{1 / 3} \operatorname{Pr}^{2 / 3} \Gamma(1 / 3)^{-1}\left\{\left(\hat{\eta}_{\mathrm{S}} / 2\right)^{1 / 3} \exp \left(-\hat{\eta}_{\mathrm{S}} / 2\right)\right. \\
& \left.+1.44 \hat{\eta}_{\mathrm{S}}\left[\gamma\left(1 / 3, \hat{\eta}_{\mathrm{S}}\right)-\Gamma(1 / 3)+1 / 3 \hat{\eta}_{\mathrm{S}}^{-2 / 3} \exp \left(-\hat{\eta}_{\mathrm{S}}\right)\right]\right\} .
\end{aligned}
$$

I again solve eq 54 for $\hat{\eta}_{\mathrm{S}}$ by Newton's method and then find $z_{\mathrm{T}} / z_{0}$ from eq 53,

$$
z_{\mathrm{T}} / z_{0}=\hat{\eta}_{\mathrm{s}}^{1 / 2}\left(\frac{9 \cdot 85 \cdot a}{\mathrm{e}^{-6} \mathrm{Pr}}\right)^{1 / 3} \exp \left[-1.458 \alpha_{\mathrm{H}} k(85 a)^{1 / 3} \operatorname{Pr}^{2 / 3} K\left(\hat{\eta}_{\mathrm{S}}\right)\right]
$$

The constant $a$ is yet to be specified. The viscous sublayer velocity profile, eq 33 , is approximately valid from the surface to the lower boundary of the inertial sublayer at $30 v / u_{*}$ (Tennekes and Lumley 1972, p. 160). Therefore, integrating this profile from zero to $30 \mathrm{v} / u_{*}$ should yield an average velocity $\bar{U}$ for the viscous sublayer. That average is $\bar{U}=15 u_{*}$. Comparing this result with eq 40, we see that $a$ should be roughly 15 . I have found that the value $a$ $=10$ fits the available data best.

Figure 5 shows model calculations of the nondimensional matching height as a function of

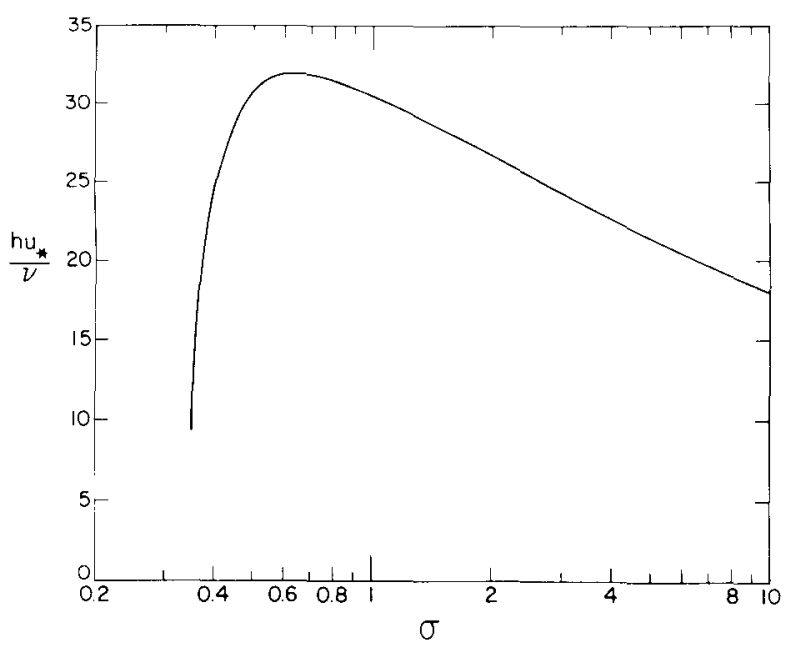

Figure 5. Nondimensional matching height over an aerodynamically smooth surface as a function of $\sigma$. 


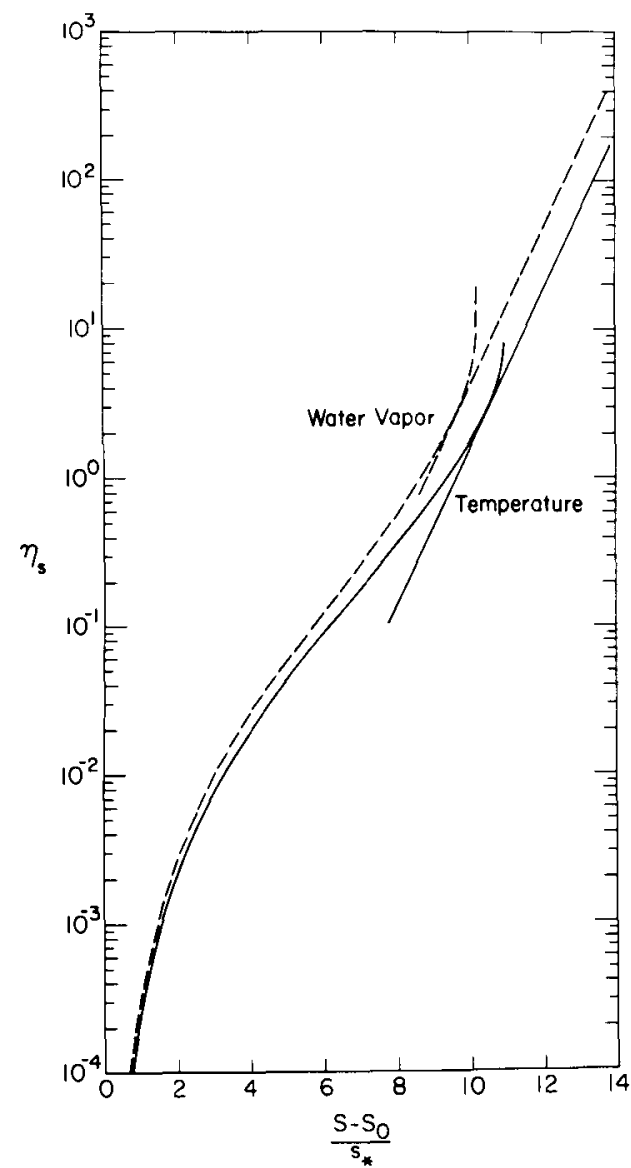

Figure 6. Matching of interfacial and inertial sublayer profiles of temperature $(\sigma$ $=0.71)$ and water vapor $(\sigma=0.63)$ over an aerodynamically smooth surface.

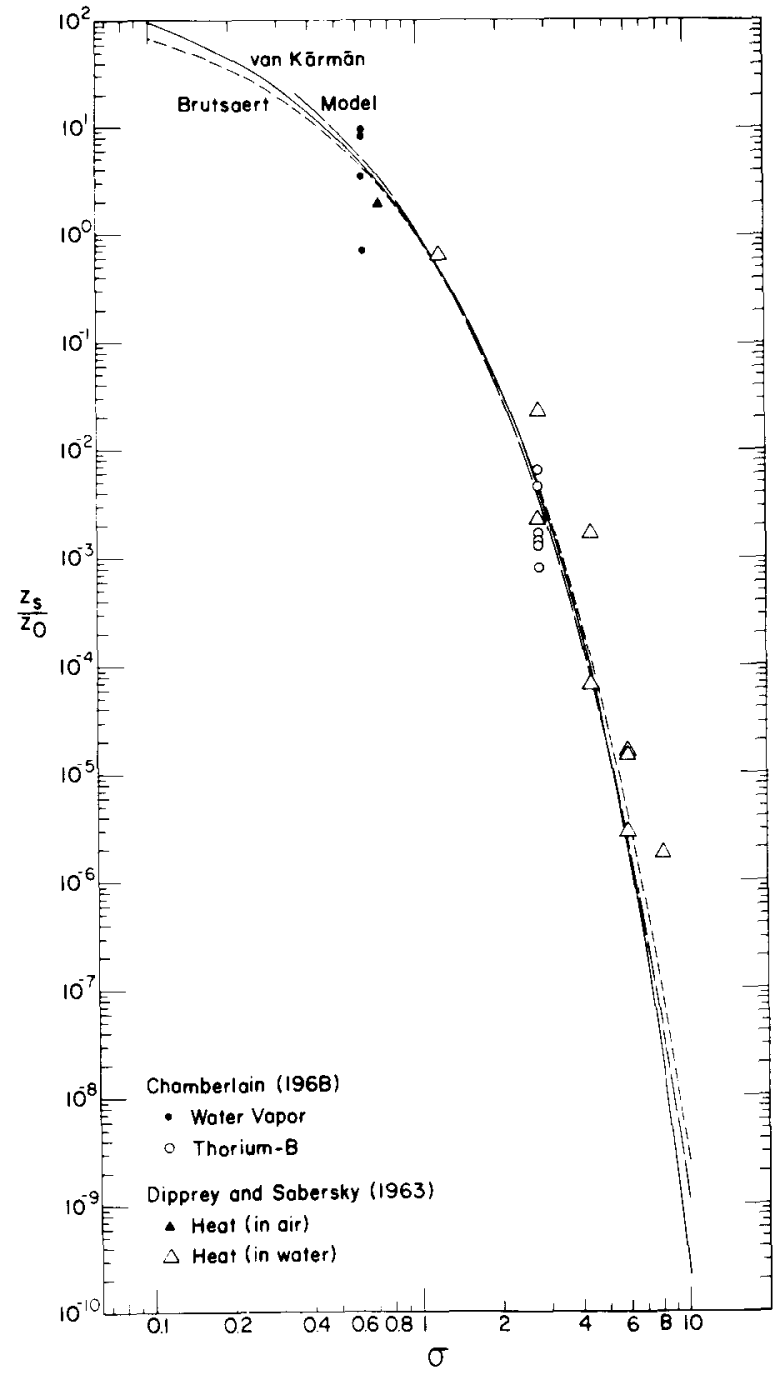

Figure 7. Current model predictions for an aerodynamically smooth surface compared with measured scalar roughness lengths for water vapor, thorium-B and heat, and with models by Brutsaert (1975b) and von Kármán (Goldstein 1965).

$\sigma$. For temperature and water vapor, the value $h u_{*} / v$ is about 32 . Brutsaert (1975a) did his matching by assuming that $h u_{*} / v=30$ for all values of $\sigma$. Figure 6 shows the matching of interfacial and inertial sublayer profiles for temperature and water vapor over an aerodynamically smooth surface. As with the aerodynamically rough surface, both profiles and their first derivatives are continuous at $h$.

Finally, Figure 7 compares my model predictions with the scanty data available from flows over smooth surfaces. In the figure the data from Chamberlain (1968) are the "smooth surface" values from his Tables 2 and 3. The data from Dipprey and Sabersky (1963) are from their smooth pipe (E-3, their Fig. 5) and from their three rough pipes (their Fig. 6-8) for runs when $R_{*} \leq 0.135$. The fourth-order polynomial

$$
\ln \left(z_{\mathrm{s}} / z_{0}\right)=0.0399-3.92 \ln \sigma-1.22(\ln \sigma)^{2}-0.254(\ln \sigma)^{3}-0.0748(\ln \sigma)^{4}
$$


is a good representation of my model results for $0.35 \leq \sigma \leq 10.0$. The figure also shows Brutsaert's (1975b) prediction,

$$
z_{\mathrm{s}} / z_{0}=\exp \left[-k\left(13.6 \sigma^{2 / 3}-13.5\right)\right],
$$

and von Kármán's (Goldstein 1965, p. 657; Monin and Yaglom 1971, p. 342),

$$
z_{\mathrm{s}} / z_{0}=\exp [-5 k\{(\sigma-1)+\ln [1+0.83(\sigma-1])\}] .
$$

The three models are so close that, with the scatter in the experimental data and their sparsity, it is impossible to decide which is best.

Notice in Figure 7 that all three models predict $z_{\mathrm{s}} / z_{0} \cong 1$ for $\sigma=1$. This is compatible with the Reynolds analogy - that over an aerodynamically smooth surface, where the roughness elements cannot cause momentum transfer through pressure forces, the transfer must be identical for momentum and for a scalar contaminant with $\sigma=1$. von Kármán (Goldstein 1965 , p. 657) explicitly assumed the validity of the Reynolds analogy and thus forced his model to predict $z_{\mathrm{s}} / z_{0}=1$ at $\sigma=1$. While neither Brutsaert $(1975 \mathrm{a}, \mathrm{b})$ nor I made this assumption, his model predicts $z_{\mathrm{s}} / z_{0}=0.96$ at $\sigma=1$, and mine predicts $z_{\mathrm{s}} / z_{0}=1.04$.

\section{SCALAR TRANSFER COEFFICIENTS}

With the results of the last two sections we can specify $z_{\mathrm{T}} / z_{0}$ and $z_{\mathrm{Q}} / z_{0}$ over snow or sea ice for all $R_{*}$ (Fig. 8). Since temperatures will be $0^{\circ} \mathrm{C}$ or less, I take the Prandtl number $(v / D)$ as 0.71 and the Schmidt number $\left(v / D_{\mathrm{w}}\right)$ as 0.63 , with values for the molecular diffusivity of water vapor, $D_{\mathrm{w}}$, taken from Pruppacher and Klett $\left(1978\right.$, p. 413). In $R_{*}$ I evaluate $v$ at $-5^{\circ} \mathrm{C}$. Because the model predicts $z_{\mathrm{S}} / z_{0}$ only over aerodynamically smooth and rough surfaces, to obtain $z_{\mathrm{s}} / z_{0}$ values in the transition region, I did a log-log interpolation between model results at $R_{*}=0.135$ and $R_{*}=2.5$.

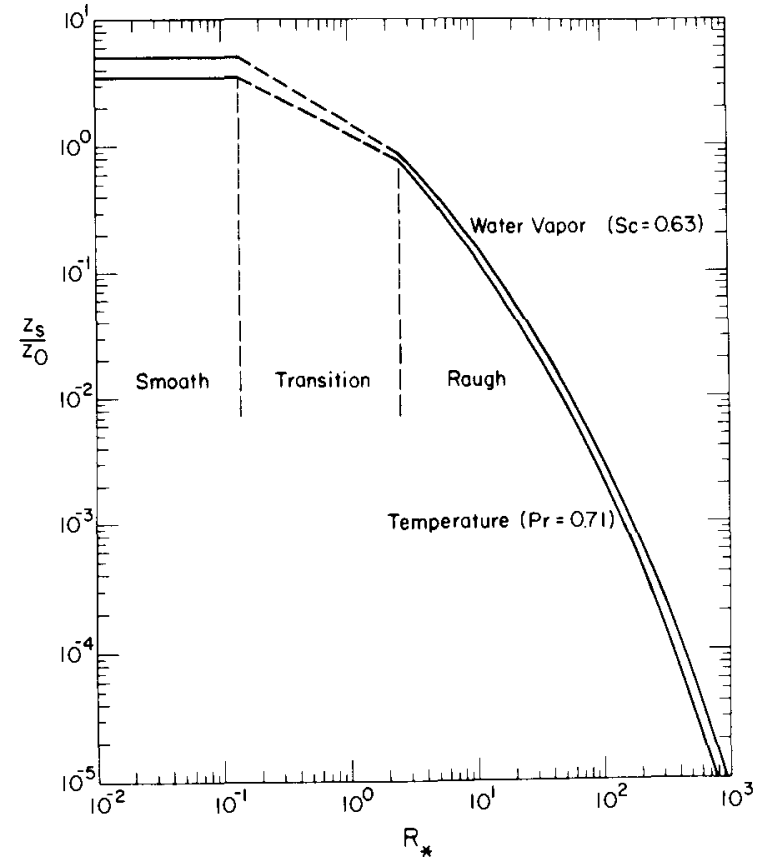

Figure 8. Model predictions of $\mathrm{z}_{T} / \mathrm{z}_{0}$ and $\mathrm{z}_{Q} / \mathrm{z}_{0}$ over snow and sea ice. 
Table 1. Values of the coefficients in the polynomials (eq 59) that predict $z_{\mathrm{s}} / z_{0}$ for temperature $(\sigma=0.71)$ and water vapor $(\sigma=0.63)$.

\begin{tabular}{lccc} 
& $\mathrm{R}_{*} \leq 0.135$ & $0.135<\mathrm{R}_{*}<2.5$ & $2.5 \leq \mathrm{R}_{*} \leq 1000$ \\
\hline \multicolumn{3}{c}{ Temperature } \\
$b_{0}$ & 1.250 & 0.149 & 0.317 \\
$b_{1}$ & - & -0.550 & -0.565 \\
$b_{2}$ & - & - & -0.183 \\
& \multicolumn{3}{c}{} \\
$b_{0}$ & 1.610 & Water vapor \\
$b_{1}$ & - & 0.351 & 0.396 \\
$b_{2}$ & - & -0.628 & -0.512 \\
\hline
\end{tabular}

Figure 8 shows that $z_{\mathrm{Q}}$ is slightly larger than $z_{\mathrm{T}}$ at all roughness Reynolds numbers. As Figures 3, 4 and 7 imply, this is strictly an effect of the difference in molecular diffusivities. Both $z_{\mathrm{T}}$ and $z_{\mathrm{Q}}$ are usually less than $z_{0} ; z_{\mathrm{T}} / z_{0}$ and $z_{\mathrm{Q}} / z_{0}$ become less than one in the transition region and decrease monotonically in the aerodynamically rough region. Thus, $z_{\mathrm{T}}$ and $z_{\mathrm{Q}}$ are virtually always less than $z_{0}$ in natural flows.

Several recent models predicted scalar transfer over aerodynamically rough surfaces. The model by Garratt and Hicks (1973)-which is just the empirical equation that Owen and Thomson (1963) derived-predicts $z_{\mathrm{s}} / z_{0}$ values generally five times larger than my model. The predictions of $z_{\mathrm{s}} / z_{0}$ by Liu et al. (1979), which admittedly are for a water surface, are almost an order of magnitude smaller than mine. Brutsaert's (1975b) model predicts $z_{\mathrm{s}} / z_{0}$ values smaller than mine for $R_{*}<20$ but values fairly close to mine for larger $R_{*}$.

For facilitating computer modeling, I have fitted the model results in Figure 8 with polynomials of the form

$$
\ln \left(z_{\mathrm{s}} / z_{0}\right)=b_{0}+b_{1} \ln R_{*}+b_{2}\left(\ln R_{*}\right)^{2}
$$

Table 1 lists the coefficients for smooth, transition and rough surfaces.

As eq 11 and 12 show, if we know $z_{\mathrm{T}} / z_{0}, z_{\mathrm{Q}} / z_{0}$ and $C_{\mathrm{D}}$, we can find $C_{\mathrm{H}}$ and $C_{\mathrm{E}}$. The model for $C_{\mathrm{D}}$ presented by Banke et al. (1980) synthesizes a representative collection of $C_{\mathrm{D}}$ values measured over a host of sea ice surfaces. Their empirical result,

$$
10^{3} C_{\mathrm{D}}=1.10+0.072 \xi
$$

parameterizes the drag coefficient in terms of the rms surface roughness $\xi$ in centimetres. Banke et al. (1980) found $\xi$ by measuring the surface elevation at $1-\mathrm{m}$ intervals for several hundred metres upwind of their instruments. Integrating the power spectrum of these data over wavelengths less than $13 \mathrm{~m}$ yielded $\xi^{2}$. The $z_{0}$ values reported by Schmidt (1982) for blowing snow and those summarized by Chamberlain (1983) for drifting snow and sand are generally in the range reported by Banke et al. (1980); hence, we assume that eq 60 is a valid model for snowfields, too.

Kind (1976) and Chamberlain (1983) suggested that roughness lengths for snow and sand obey Charnock's (1955) relation,

$$
z_{0}=\beta u_{*}^{2} / g
$$




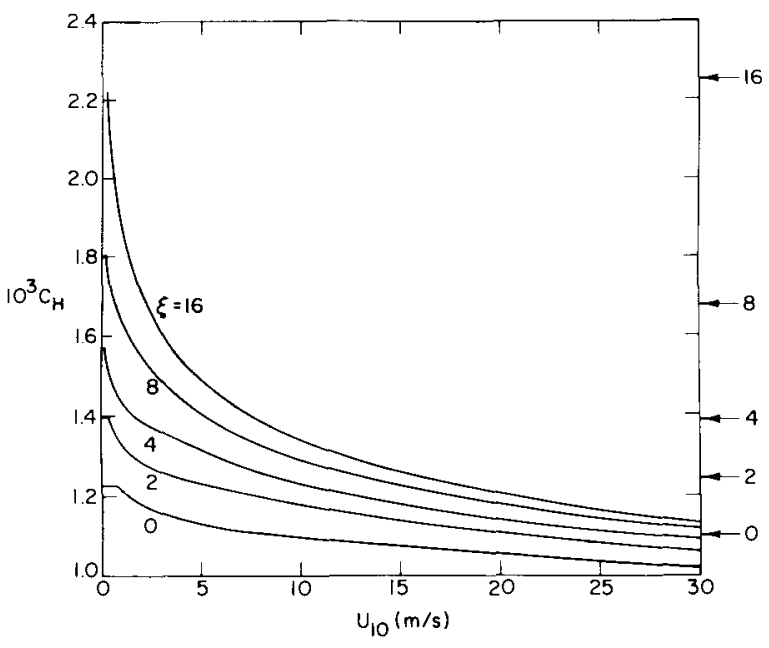

a. $\mathrm{C}_{H}$.

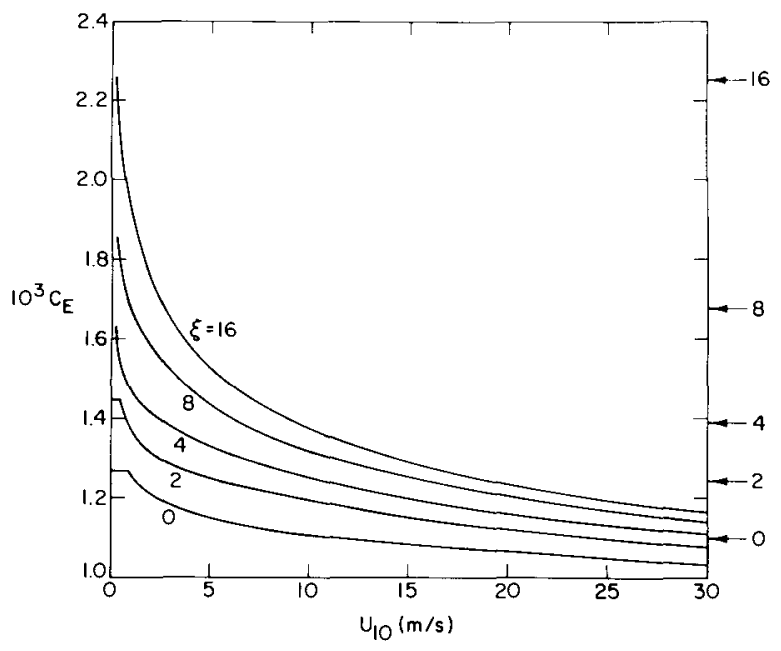

b. $\mathrm{C}_{E}$.

Figure 9. Bulk transfer coefficients for sensible $\left(\mathrm{C}_{H}\right)$ and latent $\left(\mathrm{C}_{E}\right)$ heat over snow or sea ice as a function of the rms surface roughness (in centimetres) and the 10- $m$ wind speed $\mathrm{U}_{10}$. The arrows on the right show $\mathrm{C}_{D}$ for the indicated $\xi$ value.

where $g$ is the acceleration of gravity and $\beta$ is a dimensionless constant in the range 0.010 0.016 . Through eq 10 , eq 61 would yield $C_{\mathrm{D}}$; but because eq 60 parameterizes the form drag, which as I explained is an important effect over sea ice, I prefer eq 60 to 61 .

The routine for estimating $C_{\mathrm{H}}$ and $C_{\mathrm{E}}$ is first to select a $\xi$ value; this value then defines $C_{\mathrm{D}}$ from eq 60. $C_{\mathrm{D}}$, in turn, has a one-to-one relationship with $z_{0}$ through eq 10 . Finally, we compute $R_{*}$ from

$$
R_{*}=U_{10} C_{\mathrm{D}}^{1 / 2} z_{0} / v,
$$

where $U_{10}$ is the wind speed at $10 \mathrm{~m}$. Substituting $R_{*}$ into eq 59 , we use the resulting $z_{\mathrm{T}} / z_{0}$ and $z_{\mathrm{Q}} / z_{0}$ values to compute $C_{\mathrm{H}}$ and $C_{\mathrm{E}}$ for a $10-\mathrm{m}$ reference height from eq 11 and 12 . Figure 9 shows $C_{\mathrm{H}}$ and $C_{\mathrm{E}}$ as functions of $\xi$ and $U_{10}$. Remember again, $C_{\mathrm{D}}, C_{\mathrm{H}}$ and $C_{\mathrm{E}}$ are the values at neutral stability. 
According to Figure 9, $C_{\mathrm{E}}$ is always 1-3\% larger than $C_{\mathrm{H}}$. And except for very low wind speed, when the surface is aerodynamically smooth or in transition, both are smaller than $C_{\mathrm{D}}$.

The form of the $C_{\mathrm{H}}$ and $C_{\mathrm{E}}$ functions in Figure 9 is different from that predicted by Kondo (1975) and by Liu et al. (1979) for $C_{\mathrm{H}}$ and $C_{\mathrm{E}}$ over the ocean. According to Figure $9, C_{\mathrm{H}}$ and $C_{\mathrm{E}}$ are monotonically decreasing functions of wind speed, except at very low speeds over smooth surfaces where they are constant. Kondo (1975) predicted that over the ocean $C_{\mathrm{H}}$ and $C_{\mathrm{E}}$ have minimums at about $2 \mathrm{~m} / \mathrm{s}$ and then increase gradually as the wind speed increases. Liu et al. (1979) predicted that $C_{\mathrm{H}}$ and $C_{\mathrm{E}}$ have local minimums at roughly $2 \mathrm{~m} / \mathrm{s}$, local maximums at about $5 \mathrm{~m} / \mathrm{s}$, then decrease slowly for increasing wind speeds. The basic reason for the differences between my model and these is that over the ocean $C_{\mathrm{D}}$ has a wind speed dependence. No such wind speed dependence has been established for the drag coefficient over snow or sea ice.

In Figure $9, C_{\mathrm{H}}$ and $C_{\mathrm{E}}$ are generally between $1.0 \times 10^{-3}$ and $1.5 \times 10^{-3}$. Only over the roughest surfaces-and then only at low wind speeds-are $C_{\mathrm{H}}$ and $C_{\mathrm{E}}$ larger than $1.5 \times 10^{-3}$. $C_{\mathrm{H}}$ and $C_{\mathrm{E}}$ go below $1.0 \times 10^{-3}$ only at unusually high wind speeds. The model predictions therefore cast doubt on the scalar transfer coefficients reported by Hicks and Martin (1972) and Thorpe et al. (1973). For wind speeds of about $3 \mathrm{~m} / \mathrm{s}$, Hicks and Martin (1972) found average values of $C_{\mathrm{H}}$ and $C_{\mathrm{E}}$ over snow-covered Lake Mendota to be $0.9 \times 10^{-3}$ and $2.5 \times 10^{-3}$ respectively. Over ice in the Beaufort Sea, Thorpe et al. (1973) found averages of $C_{\mathrm{H}}=$ $1.2 \times 10^{-3}$ and $C_{\mathrm{E}}=0.55 \times 10^{-3}$ for winds ranging from 5 to $10 \mathrm{~m} / \mathrm{s}$. Only the $C_{\mathrm{H}}$ measurement by Thorpe et al. (1973) is compatible with theoretical predictions.

I do not mean here to deprecate the efforts of these scientists; measuring $C_{\mathrm{H}}$ and $C_{\mathrm{E}}$ over natural snow and sea ice surfaces is an important but extremely difficult job. First, you have

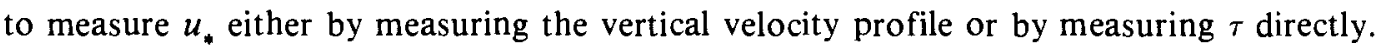
Next, you must measure $t_{*}$ and $q_{*}$-again, either by measuring the vertical profiles of temperature and water vapor or by measuring $H_{\mathrm{s}}$ and $H_{\mathrm{L}}$ directly. These are necessary not only for finding $C_{\mathrm{H}}$ and $C_{\mathrm{E}}$ but also for making stability corrections. Last, and probably most important, is the measurement of $T_{0}$ and $Q_{0}$. Since $T_{0}-T_{\mathrm{r}}$ and $Q_{0}-Q_{\mathrm{r}}$ are rarely large over frozen surfaces, the $T_{0}$ and $Q_{0}$ measurements must be precise. But because the surface is illdefined, simply deciding what level over the snow corresponds to $T_{0}$ and $Q_{0}$ is a problem; finding instruments capable of measuring $T_{0}$ and $Q_{0}$ without disturbing the integrity of the surface is another. Consequently, the most careful flux measurements are of little value for specifying $C_{\mathrm{H}}$ and $C_{\mathrm{E}}$ if $T_{0}$ and $Q_{0}$ are not measured as carefully.

\section{CONCLUSIONS}

I have modeled the transfer of the passive scalar contaminants temperature and water vapor over aerodynamically rough and smooth snow and sea ice surfaces. The basis of the model is a smooth matching of interfacial and inertial sublayer profiles. The inertial sublayer profile has the usual semi-logarithmic form; I derive the interfacial sublayer profiles over smooth and rough surfaces on the basis of a turbulent surface-renewal model. This, I think, is the first such derivation of the interfacial sublayer profile for a passive scalar over an aerodynamically smooth surface.

The model yields values of $z_{\mathrm{T}} / z_{0}$ and $z_{\mathrm{Q}} / z_{0}$ as functions of the roughness Reynolds number. Using these values and the empirical model for the drag coefficient over sea ice given by Banke et al. (1980), I predict the bulk coefficients for sensible $\left(C_{\mathrm{H}}\right)$ and latent $\left(C_{\mathrm{E}}\right)$ heat at neutral stability over snow and sea ice. These depend on the wind speed and on a surface roughness parameter. $C_{\mathrm{E}}$ is $1-3 \%$ larger than $C_{\mathrm{H}}$; at wind speeds greater than $3 \mathrm{~m} / \mathrm{s}$ both are virtually always between $1.0 \times 10^{-3}$ and $1.5 \times 10^{-3}$. Only at low wind speeds-which usually do not persist-and over very rough surfaces are $C_{\mathrm{H}}$ and $C_{\mathrm{E}}$ larger than $1.5 \times 10^{-3}$. 


\section{LITERATURE CITED}

Abramowitz, M. and I.A. Stegun (Ed.) (1965) Handbook of Mathematical Functions. New York: Dover.

Andreas, E.L and S.F. Ackley (1982) On the differences in ablation seasons of Arctic and Antarctic sea ice. Journal of the Atmospheric Sciences, 39: 440-447.

Arya, S.P.S. (1973) Contribution of form drag on pressure ridges to the air stress on Arctic ice. Journal of Geophysical Research, 78: 7092-7099.

Arya, S.P.S. (1975) A drag partition theory for determining the large-scale roughness parameter and wind stress on the Arctic pack ice. Journal of Geophysical Research, 80: 34473454.

Banke, E.G., S.D. Smith and R.J. Anderson (1980) Drag coefficients at AIDJEX from sonic anemometer measurements. In Sea Ice Processes and Models (R.S. Pritchard, Ed.). Seattle: University of Washington Press, pp. 430-442.

Bradley, E.F. (1972) The influence of thermal stability on a drag coefficient measured close to the ground. Agricultural Meteorology, 9: 183-190.

Brutsaert, W. (1975a) A theory for local evaporation (or heat transfer) from rough and smooth surfaces at ground level. Water Resources Research, 11: 543-550.

Brutsaert, W. (1975b) The roughness length for water vapor, sensible heat, and other scalars. Journal of the Atmospheric Sciences, 32: 2028-2031.

Businger, J.A. (1973) Turbulent transfer in the atmospheric surface layer. In Workshop on Micrometeorology (D.A. Haugen, Ed.). Boston: American Meteorological Society, pp. 67-100.

Businger, J.A., J.C. Wyngaard, Y. Izumi and E.F. Bradley (1971) Flux-profile relationships in the atmospheric surface layer. Journal of the Atmospheric Sciences, 28: 181-189.

Chamberlain, A.C. (1966) Transport of gases to and from grass and grass-like surfaces. Proceedings of the Royal Society, London, A290: 236-265.

Chamberlain, A.C. (1968) Transport of gases to and from surfaces with bluff and wave-like roughness elements. Quarterly Journal of the Royal Meteorological Society, 94: 318-332.

Chamberlain, A.C. (1983) Roughness length of sea, sand, and snow. Boundary-Layer Meteorology, 25: 405-409.

Charnock, H. (1955) Wind stress on water: An hypothesis. Quarterly Journal of the Royal Meteorological Society, 81: 639.

Danckwerts, P.V. (1951) Significance of liquid-film coefficients in gas absorption. Industrial Engineering Chemistry, 43: 1460-1467.

Danckwerts, P.V. (1970) Gas-Liquid Reactions. New York: McGraw-Hill.

Deardorff, J.W. (1968) Dependence of air-sea transfer coefficients on bulk stability. Journal of Geophysical Research, 73: 2549-2557.

Dennery, P. and A. Krzywicki (1967) Mathematics for Physicists. New York: Harper and Row.

Dipprey, D.F. and R.H. Sabersky (1963) Heat and momentum transfer in smooth and rough tubes at various Prandtl numbers. International Journal of Heat and Mass Transfer, 6: 329353.

Duff, G.F.D. and D. Naylor (1966) Differential Equations of Applied Mathematics. New York: John Wiley and Sons.

Dyer, A.J. (1974) A review of flux-profile relationships. Boundary-Layer Meteorology, 7: 363-372.

Garratt, J.R. and B.B. Hicks (1973) Momentum, heat and water vapour transfer to and from natural and artificial surfaces. Quarterly Journal of the Royal Meteorological Society, 99: 680-687. 
Goldstein, S. (Ed.) (1965) Modern Developments in Fluid Dynamics. New York: Dover. Grass, A.J. (1971) Structural features of turbulent flow over smooth and rough boundaries. Journal of Fluid Mechanics, 50: 233-255.

Hibler, W.D. III (1980) Modeling a variable thickness sea ice cover. Monthly Weather Review, 108: 1943-1973.

Hicks, B.B. and H.C. Martin (1972) Atmospheric turbulent fluxes over snow. BoundaryLayer Meteorology, 2: 496-502.

Hill, R.J. (1978) Spectra of fluctuations in refractivity, temperature, humidity, and the temperature-humidity cospectrum in the inertial and dissipation ranges. Radio Science, 13: 953961.

Kestin, J. and L.N. Persen (1962) The transfer of heat across a turbulent boundary layer at very high Prandtl numbers. International Journal of Heat and Mass Transfer, 5: 355-371.

Khundzhua, G.G. and Ye.G. Andreyev (1974) An experimental study of heat exchange between the ocean and the atmosphere in small-scale interaction. Izvestiya, Atmospheric and Oceanic Physics, 10: 685-687.

Kim, H.T., S.J. Kline and W.C. Reynolds (1971) The production of turbulence near a smooth wall in a turbulent boundary layer. Journal of Fluid Mechanics, 50: 133-160.

Kind, R.J. (1976) A critical examination of the requirements for model simulation of windinduced erosion/deposition phenomena such as drifting snow. Atmospheric Environment, 10: 219-227.

Kondo, J. (1975) Air-sea bulk transfer coefficients in diabatic conditions. Boundary-Layer Meteorology, 9: 91-112.

Large, W.G. and S. Pond (1982) Sensible and latent heat flux measurements over the ocean. Journal of Physical Oceanography, 12: 464-482.

Leavitt, E., D. Bell, M. Clarke, R. Anderson and C. Paulson (1977) Computation of air stress and sensible heat fluxes from surface layer profile data, AIDJEX, 1975. AIDJEX Bulletin, 36: 157-174.

Lettau, H.H. (1979) Wind and temperature profile prediction for diabatic surface layers including strong inversion cases. Boundary-Layer Meteorology, 17: 443-464.

Liu, W.T. and J.A. Businger (1975) Temperature profile in the molecular sublayer near the interface of a fluid in turbulent motion. Geophysical Research Letters, 2: 403-404.

Liu, W.T., K.B. Katsaros and J.A. Businger (1979) Bulk parameterization of air-sea exchanges of heat and water vapor including the molecular constraints at the interface. Journal of the Atmospheric Sciences, 36: 1722-1735.

Mangarella, P.A., A.J. Chambers, R.L. Street and E.Y. Hsu (1973) Laboratory studies of evaporation and energy transfer through a wavy air-water interface. Journal of Physical Oceanography, 3: 93-101.

Maykut, G.A. (1978) Energy exchange over young sea ice in the Central Arctic. Journal of Geophysical Research, 83: 3646-3658.

Monin, A.S. and A.M. Yaglom (1971) Statistical Fluid Mechanics: Mechanics of Turbulence. Vol. 1. Cambridge, Massachusetts: MIT Press.

Owen, P.R. and W.R. Thomson (1963) Heat transfer across rough surfaces. Journal of Fluid Mechanics, 15: 321-334.

Parkinson, C.L. and W.M. Washington (1979) A large-scale numerical model of sea ice. Journal of Geophysical Research, 84: 311-337.

Paulson, C.A. (1970) The mathematical representation of wind speed and temperature profiles in the unstable atmospheric surface layer. Journal of Applied Meteorology, 9: 857-861.

Pruppacher, H.R. and J.D. Klett (1978) Microphysics of Clouds and Precipitation. Dordrecht: Reidel. 
Schlichting, H. (1968) Boundary-Layer Theory (Translated by J. Kestin). Sixth edition. New York: McGraw-Hill.

Schmidt, R.A. (1982) Vertical profiles of wind speed, snow concentration, and humidity in blowing snow. Boundary-Layer Meteorology, 23: 223-246.

Tennekes, H. and J.L. Lumley (1972) A First Course in Turbulence. Cambridge, Massachusetts: MIT Press.

Thorpe, M.R., E.G. Banke and S.D. Smith (1973) Eddy correlation measurements of evaporation and sensible heat flux over Arctic sea ice. Journal of Geophysical Research, 78: 3573-3584.

Untersteiner, N. and F.I. Badgley (1965) The roughness parameter of sea ice. Journal of Geophysical Research, 70: 4573-4577. 